\title{
Should elderly patients be told they have cancer? Questionnaire survey of older people
}

\author{
A Ajaj, M P Singh, A JJ Abdulla
}

Department of Elderly Care, Mid-Staffordshire General Hospitals, Stafford ST18 3SA A Ajaj specialist registrar M P Singh senior house officer A JJ Abdulla consultant physician

Correspondence to: Dr AJJ Abdulla, Department of Elderly Medicine, Orpington Hospital, Orpington, Kent BR6 9JU

(AzaAbdulla@ bromleyh-tr.sthames. nhs.uk)

BMJ 2001;323:1160
There is evidence that doctors fail to inform patients when they diagnose cancer ${ }^{1-3}$ and that this is more likely in older people. Yet Meredith et al showed that $96 \%$ of 250 patients with malignancy wanted to know if their illness was cancer. ${ }^{4}$ Although it is now appreciated that patients want more information about their illness, few studies have specifically targeted elderly people to assess their opinions about cancer and how much they would wish to know about their diagnosis.

\section{Patients and methods}

We produced a questionnaire asking older people's views on how much they would want to know, if they were diagnosed with cancer, about the type of cancer, extent of spread, treatment, and prognosis and also their wishes about informing their families. We also inquired about mobility and living circumstances to determine any association. Patients were recruited from day hospitals and outpatient clinics (74\%, $\mathrm{n}=199)$ and from the local senior citizen association $(26 \%, \mathrm{n}=71)$. Patients with dementia or a history of cancer were excluded.

Of a total of 315 individuals approached, 270 $(86 \%)$ completed the questionnaire. Respondents ranged in age from 65 to 94 years (mean 79.9 (SD 8.3) years) with $54 \%(\mathrm{n}=145)$ over 75 . Over half were women $(58 \%, \mathrm{n}=156)$. Altogether $238(88 \%)$ respondents wanted to be informed of the diagnosis, whereas $11 \%$ did not and $1 \%$ were indifferent. A significant difference was noted between those aged under 75 and those aged 75 or over in the proportion who did not want to be informed $(6.4 \%$ and $13.7 \%$ respectively, $\mathrm{P}=0.04$ ). Of those who expressed a desire to be informed, $62 \%(\mathrm{n}=147)$ wanted to know as much as possible about their cancer, whereas the remainder were more selective. Over $70 \%(\mathrm{n}=194)$ of respondents wanted their relatives to be informed when the diagnosis of cancer was made.

No significant differences in attitude towards being told about cancer were found between those with different living circumstances or those who lived with a partner or not. In contrast, individuals with limited mobility were significantly less interested in knowing they had cancer than those who walked independently either unaided or with a stick $(7 \% v 28 \%, \mathrm{P}=0.002)$. This, we believe, is important as mobility could be taken to reflect independence. There was no relation, however, to walking distance, as a substantial proportion (44\%) could walk only 23 metres or less.

\section{Comment}

Eighty eight per cent of our population of older people living in the community would like to be told if they developed cancer. This compares with $96 \%$ in a previous study of patients with cancer. ${ }^{4}$ The difference is probably related to the fact that all the patients in the previous study had cancer (whereas ours did not), and they represented a wider age group, with only $44 \%$ being aged over 65 years. Most of our population wanted their families to be informed, although a few commented that they would rather tell them themselves. In contrast, $28 \%(\mathrm{n}=76)$ did not wish their family to know, and this relatively high proportion probably reflects the fact that $45 \%$ were widowed and $52 \%$ lived alone. Disclosure of a diagnosis of cancer has on occasions caused conflict between physicians and family members. Our study clarifies this issue and should help decision making in the difficult situation where family members ask that their elderly relatives should not be informed. We are not aware of studies among elderly patients with cancer, and a study among this group is now required to provide a more comprehensive picture.

AJJA conceived the study and designed and produced the questionnaire. MS and AA did the patient interviews and collected the data. All three authors wrote the paper. AJJA is guarantor.

Competing interests: none declared.

1 Mosconi P, Meyerowitz BE, Liberati MC, Liberati A. Disclosure of breast cancer diagnosis, patients and physicians reports. Ann Oncol 1991;2: 273-80

2 Thompsen OO, Wulff HR, Martin A, Singer PA. What do gastroenterologist in Europe tell cancer patients? Lancet 1993;341:473-6.

3 Wilkes E. The quality of life. In: Doyle D, ed. Palliative care: the management of far advanced illness. Philadelphia: Crohel, 1984.

4 Meredith C, Symonds P, Webster L, Lamont D, Pyper E, Gillis CR, et al. Information needs of cancer patients in west Scotland: cross sectional survey of patients' views. BMJ 1996;313:724-6.

(Accepted 18 September 2001)

One hundred years ago

The campaign against rats

In these days of plague and rumours of plague the rat seems to be giving as much trouble to some sanitary authorities as the Boers are giving to Lord Kitchener. In Capetown a price has been set upon their heads, and poison intended for their consumption has been laid down in all the city sewers. The Health Committee of Cardiff has organised a campaign against the rodents, and has taken the field with a large force of researchers and an imposing matériel in the way of traps. From day to day we read that the rats are hard pressed like De Wet, but they are as "slim" as that elusive General, and correspondents fresh from the fields of "regrettable incidents" in South Africa are beginning to speak of "a muddled campaign." From a corporation to a commander-in-chief nothing is sacred to your halfpenny journalist. But it must be admitted that so far in its war against rats the Cardiff Corporation has had no better fortune than that of Hamelin, and it is not likely that a Pied Piper will come to the rescue.

(BMJ 1901;i:417) 